ISSN electrónico 2011-2629.

ISSN impreso 0121-3709.

http://doi.org/10.22579/20112629.596

\title{
Caracterización y tipificación socioeconómica en productores de cultivos transitorios ubicados en Piedemonte y Altillanura plana ${ }^{1}$
}

\author{
Characterising and socioeconomic classification of transitory crop \\ producers working in the Piedmont area of Colombia's Eastern plains \\ and flat high plains areas
}

\section{Caracterização e classificação socioeconômica em produtores de culturas transitórias localizadas em Piedemonte e Altillanura plana}

\author{
Adriana M. Molina-Romero ${ }^{1 *}$, Manuel E. Ostos-Triana ${ }^{2 *}$, Mario S. Buenaventura-Baron ${ }^{3 *}$, \\ Jorge H. Argüelles-Cárdenas ${ }^{*}$ \\ 1 Econ, MSc \\ 2 Prof. Mercd. Agrop \\ 3 Ing. Agrón, Esp. Desarrollo de Mercados \\ 4 Ing. Agrón, MSc \\ * Corporación Colombiana de Investigación Agropecuaria-AGROSAVIA. C.I. La Libertad, Km 17 vía Puerto López, \\ Colombia \\ Email: amolinar@agrosavia.co
}

Recibido: 05 de noviembre de 2019

Aceptado: 13 de abril de 2020

\section{Resumen}

En este trabajo se realizó una tipificación y caracterización socioeconómica de los productores de cultivos transitorios de arroz, maíz y soya, mediante una encuesta estructurada realizada en el semestre 2019A en las zonas del Piedemonte Llanero y la Altillanura plana, complementada con información general de los gremios de la producción (Fenalce, Fedearroz) y Agrosavia, para mejorar y orientar las políticas institucionales y sectoriales acordes a las condiciones actuales de los productores. Se determinó un tamaño de muestra mediante muestreo estratificado con asignación proporcional, con un margen de error de 5\% y un nivel de confianza del 95\%, para un total de 85 productores, de los cuales 62 están ubicados en el Piedemonte y 23 en la Altillanura. La clasificación de los productores se realizó mediante dos técnicas multivariadas: análisis de correspondencia múltiple (ACM) y análisis de conglomerados jerárquico (AC), en grupos homogéneos, con dieciocho (18) variables sociales y económicas relacionadas con el sistema productivo. Los resultados permitieron generar cinco grupos de productores los cuales fueron tipificados y caracterizados en: 1) productores mayormente maiceros con

El presente artículo es resultado de la investigación realizada por AGROSAVIA con agricultores de cultivos transitorios bajo la fase I de la agenda corporativa 2018 - 2019 en el C.I. La Libertad.

Como Citar (Norma Vancouver):

Molina-Romero AM, Ostos-Triana ME, Buenaventura-Baron MS, Argüelles-Cárdenas JH. Caracterización y tipificación socioeconómica en productores de cultivos transitorios ubicados en Piedemonte y Altillanura plana. Orinoquia,2020;24(1): 113-127. DOI: http://doi.org/10.22579/20112629.596 
niveles altos de ingreso y educación superior $(n=18), 2)$ maiceros y soyeros con mayor uso de mano de obra familiar y dependencia financiera de casas comerciales $(n=16), 3)$ mayormente soyeros con gran experiencia y edad $(n=18)$, 4) mayormente arroceros con nivel básica primaria y con vías despavimentadas ( $n=27)$ y 5$)$ maiceros y arroceros vinculados al SISBEN y con uso de los recursos de inversión propia $(n=6)$.

Palabras claves: Orinoquia; sistemas agrícolas; cluster; cultivo ciclo corto; análisis multivariado

\begin{abstract}
This work involved the socioeconomic typing and characterisation of transitory rice, corn and soybean crop producers in the Piedmont area of Colombia's Eastern plains and flat high plains areas through a structured survey carried out during the 2019A semester. This was complemented by general information provided by the trade/producers' associations (Fenalce (cereal growers' association) and Fedearroz (rice growers' federation)) and the Colombian Agricultural Research Corporation (Agrosavia) to improve and guide institutional and sector policies according to the producers' current conditions. Sample size was determined by stratified sampling with proportional allocation (5\% margin of error and $95 \%$ confidence level); this gave 85 producers, 62 of whom were located in the Piedmont area and 23 on the high plains. The producers were classified into homogeneous groups using multiple correspondence analysis (MCA) and hierarchical cluster analysis (CA) multivariate techniques, with eighteen production-system-related social and economic variables. The results led to typing and characterising five groups of producers: 1) those having high income and higher education levels (mainly corn farmers) ( $\mathrm{n}=18), 2$ ) corn and soybean farmers relying on greater use of family labour and being dependent on banks/financial institutions $(n=16), 3)$ mostly older soy farmers having great experience $(n=18)$, 4) mostly rice farmers having basic primary education and unpaved roads $(n=27)$ and 5$)$ corn and rice farmers linked to Colombia's system of identifying social programme beneficiaries (SISBEN) using their own investment resources $(n=6)$.
\end{abstract}

Key words: Orinoquia; agricultural system; cluster; short cycle cultivation; multivariate analysis.

\title{
Resumo
}

Neste trabalho, foi realizada uma tipificação e caracterização socioeconômica dos produtores de culturas temporárias de arroz, milho e soja, por meio de uma pesquisa estruturada realizada no semestre de 2019A nas áreas do Piedemonte e Altillanura plana, complementada com informações gerais sobre as guildas de produção (Fenalce, Fedearroz) e Agrosavia, para melhorar e orientar as políticas institucionais e setoriais de acordo com as condições atuais dos produtores. O tamanho da amostra foi determinado através de amostragem estratificada com alocação proporcional, com margem de erro de $5 \%$ e nível de confiança de 95\%, para um total de 85 produtores, dos quais 62 estão localizados no Piedemonte e 23 na Altillanura. Os produtores foram classificados usando duas técnicas multivariadas: análise de correspondência múltipla (ACM) e análise hierárquica de cluster (CA), em grupos homogêneos, com dezoito (18) variáveis sociais e econômicas relacionadas ao sistema de produção. Os resultados permitiram gerar cinco grupos de produtores que foram tipificados e caracterizados em: 1) produtores principalmente de milho com alto nível de renda e ensino superior $(\mathrm{n}=18), 2)$ produtores de milho e soja com maior uso da mão-de-obra familiar e dependência financeira de casas comerciais $(n=16), 3)$ agricultores de soja com ampla experiência e idade $(n=18), 4)$ arrozeiros com nível primário básico e com estradas não pavimentadas $(n=27)$ e 5$)$ produtores de milho e arroz vinculados ao SISBEN e utilizando recursos de investimento próprio ( $n=6)$.

Palavras-chave: Orinoquia; sistemas agrícolas; cluster; cultivo de ciclo curto; análise multivariada

\section{Introducción}

Colombia tiene un alto potencial para expandir su zona agrícola sin que esto interfiera con las zonas de bosque natural, de acuerdo con Finagro (2014), así mismo, la FAO (2011) calcula que 2.600 millones de hectáreas en el mundo no se están aprovechando y que Colombia es el cuarto país de Latinoamérica que cuenta con tierras libres para utilizarlas en el sector agrícola.

La producción nacional de huevos es de $14.600 \mathrm{mi}-$ llones al año y 1,6 millones de toneladas de carne de pollo, lo que genera un consumo per capital de 294 huevos y $34 \mathrm{Kg}$ de pollo. Para producir estos volúmenes se requieren 585 mil toneladas de frijol-soya, 1,3 millones toneladas torta de soya y 5 millones de toneladas de maíz amarillo, de los cuales gran parte de estas materias primas son importadas. (MARD, 2019)

La diversidad geográfica colombiana crea un abanico productivo que permite un desarrollo comercial en diferentes regiones. La Orinoquia específicamente abarca un tercio del territorio colombiano y cuenta con una gran fuente hídrica proporcionada por la cuenca del rio Orinoco, generando paisajes como la Altillanura y Piedemonte llanero que sobresalen por su gran desarrollo económico y productivo. Para el 2018, del total de la producción nacional de granos y cereales en estos dos paisajes, el $40.6 \%$ corresponde a la producción de arroz, el $27.3 \%$ a maíz amarillo y $87.2 \%$ 
a soya, de acuerdo a cálculos con cifras de Fenalce y Fedearroz (2018).

Estas dos entidades gremiales dentro sus actividades misionales generan información de los cultivos representados y contribuyen a orientar el mejoramiento de la competitividad y la eficiencia económica de los productores.

Los productores agrícolas, han estado afectados directamente con problemáticas de tipo productivo (riego, erosión del suelo, plagas, enfermedades). Sin embargo, la medición de variables sociales y económicas en las que el productor desarrolla sus actividades, no son bien conocidas por las entidades de planificación regional y nacional (Escobar y Berdegué, 1990). Este desconocimiento hace que muchas de las políticas trazadas y ofertas tecnológicas desarrolladas no cristalicen en los resultados esperados.

En la literatura, se destacan los siguientes estudios, como el de Fedearroz (2011) para los Llanos Orientales, caracterizando este sector, en aspectos de tipo agroecológico y las condiciones políticas, económicas y sociales relevantes para el cultivo, dando como resultado que los productores presentan diferentes características socioculturales al interior de las regiones. Así mismo, en el 2010 se efectuó un estudio socioeconómico de la cadena productiva del arroz en Colombia para resaltar la importancia que estos aspectos generan al sector arrocero, donde se aprecia que encadenamiento productivo del arroz es una alternativa viable para generar valor agregado, empleo e ingresos a los hogares, FENALCE (2005) realizó un estudio socioeconómico de las familias productoras de trigo en los Departamentos de Nariño, Boyacá y Cundinamarca, correspondientes a las siembras del semestre A 2005 con el fin de generar aportes estratégicos que mejoren la calidad de vida de los productores donde se concluyó la alta presencia de servicios públicos domiciliarios, poca formación academia y buena vinculación al servicio de salud por régimen subsidiado (SISBEN) para los productores de trigo.

A nivel Corporativo desde 1999 se ha investigado sobre las características de los sistemas de producción agropecuarios en los municipios de Granada y Cumaral en el departamento de Meta, con base en variables relacionadas con los componentes socioeconómico y Biofísico para plantear alternativas de desarrollo tecnológico. Luego, en el 2003 con el programa PRONATTA se caracterizó socioeconómicamente a los pequeños productores de Granada y Fuente de Oro (Meta) como herramienta para el análisis hedónico de la productividad del suelo, destacando el uso del crédi- to para financiar las labores agropecuarias generando mayores ingresos.

Escobar y Berdegué (1990) presentaron la tipificación de sistemas productivos agrícolas, durante el periodo de 1986 y 1989, con el objeto de elevar la calidad de la investigación que se realiza en América Latina, en sistemas de finca de pequeños agricultores.

El objetivo del presente estudio fue identificar el comportamiento social y económico de los diferentes productores de cultivos transitorios (arroz, maíz y soya) para el semestre 2019A ubicados en las subregiones del Piedemonte y la Altillanura, utilizando herramientas estadísticas, que permitieron generar grupos homogéneos, con el fin de ayudar a la planeación, la formulación y la ejecución de proyectos de investigaciones futuras, así como a redireccionar o replantear las políticas y planes de desarrollo para mejorar las estrategias y toma de decisiones.

\section{Materiales y métodos}

Para la caracterización y tipificación de los productores de cultivos transitorios se siguió la metodología definida por Valerio et al., (2004), frecuentemente utilizada para estos estudios como se reflejan en los trabajos de Vargas et al., (2013), Smith et al., (2013) y González (2013), permitiendo reducir el tamaño y la dimensión de las variables analizadas, para ayudar al establecimiento de tipologías diferenciadoras.

Esta metodología está estructurada en 8 etapas, dado el orden en que se maneja este trabajo las cinco primeras se desarrollaron en esta sección y las otras tres restantes se analizaron en la sección de resultados.

\section{Descripción de la población a estudiar}

La población objetivo correspondió a productores dueños de los cultivos de arroz, maíz y soya en el Piedemonte llanero (Fuente de oro, Granada y Villavicencio) y la Altillanura (Puerto López y Puerto Gaitán) durante el semestre 2019A. El marco muestral fue construido con base en los registros de productores (capacitaciones, socializaciones de resultados, días de campo, visitas al centro) incluidos los proyectos realizados por la Corporación durante los últimos años e información suministrada por los gremios de Fenalce y Fedearroz.

\section{Selección de la muestra y construcción del instrumento de recolección de la información}

Para definir la metodología de muestreo y determinar el tamaño de muestra, se partió del hecho que el pro- 
ductor utilice como estrategia productiva realizar o no rotación en los cultivos. Por lo tanto, se consideró un tamaño de muestra de forma aleatoria, estratificada con asignación proporcional al tamaño del estrato, que hace referencia al número de agricultores pertenecientes a la región de Piedemonte y Altillanura, con base en las fórmulas utilizadas en el trabajo de Calderón et al., (2019) y descritas por Scheaffer y Mendenhall (2006).

Tamaño de muestra total

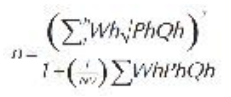

Tamaño de muestra por estrato (afijación óptima)

$$
n f_{i}=n \frac{W h \overline{P h Q h}}{\sum_{i}^{i} W h_{1} P h Q h}
$$

Donde:

$n: \quad$ Tamaño total de muestra

Wh: Peso relativo del estrato $=$ \# agricultores estrato $/ \#$ agricultores de la población.

Ph: Proporción estimada de agricultores que rotan

Qh: Proporción estimada de agricultores que no rotan

N: Tamaño de la población

$V=$ (Error de estimación/Valor de Z teórico que depende el coeficiente de confianza)

nh: Tamaño de muestra para cada estrato.

\section{Procesamiento de datos (elaboración de la base de datos, identificación y clasificación de las variables)}

Como herramienta para la captura de los datos, se elaboró una encuesta estructurada donde se identificó los aspectos básicos, variables sociales y económicas relevantes del productor de cultivos transitorios, específicamente en arroz, maíz y soya.

Con el propósito de clasificar los predios encuestados, con base en las variables socioeconómicas de carácter categórico, se realizó inicialmente un análisis de correspondencias múltiples, que de acuerdo con Diaz (2002), es un análisis de correspondencia simple aplicado no solo a una tabla de contingencia, sino a una tabla disyuntiva completa en la que una variable categórica asigna a cada individuo de una población una modalidad en la que particiona de manera disyuntiva y exhaustiva, a los individuos de una población.

\section{Revisión y selección de las variables}

Las variables incluidas en el análisis correspondieron a: nivel de escolaridad, utilización de recursos propios para el proceso productivo, afiliación a una EPS, utilización de recursos provenientes de una casa comercial, estado civil del productor, cultivo predominantes en el proceso productivo, número de familiares que habitan el predio, lugar de venta de la cosecha, número de trabajadores permanentes, número de trabajadores temporales, tipo de tenencia de la tierra, energía eléctrica y estado de las vías de acceso al predio. En la tabla 1 , se relacionan las variables sociales, económicas y agronómicas con sus respectivas categorías.

\section{Aplicación de técnicas estadísticas multivariadas}

El análisis de correspondencia múltiple se realizó mediante la utilización del procedimiento CORRESP del software SAS (Statistical Analysis System), versión 9.4. Con base en este análisis, se seleccionó un grupo de factores o dimensiones que acumularon alrededor del $50 \%$ de la variabilidad contenida en el conjunto de datos original asociadas a las variables de estudio. Con base en los factores seleccionados, se realizó un análisis de conglomerado, mediante la utilización del procedimiento CLUSTER jerárquico (algoritmo de Ward), del software mencionado, que permitió clasificar los predios en grupos homogéneos, los cuales fueron posteriormente tipificados y caracterizados con base en la utilización de tablas de contingencia, de los grupos con las categorías de las variables utilizadas en el análisis, y de las medias para las variables cuantitativas edad del productor, Ingreso, experiencia del productor, área de la finca y área de siembra. Estos análisis se realizaron mediante los procedimientos FREQ y MEANS de SAS, respectivamente.

\section{Resultados}

De acuerdo con la metodología de muestreo planteada, muestreo aleatorio estratificado con asignación proporcional, se determinó el tamaño de muestra asumiendo un error de estimación del $5 \%$ y un coeficiente de confianza del $95 \%$, para estimar la proporción de agricultores que rotan cultivos; dicho tamaño fue de 85 agricultores distribuidos de la siguiente manera: 62 productores para la región del Piedemonte y 23 para la región de la Altillanura.

Con base en los resultados generados de la encuesta, se realizó la caracterización de los agricultores que cultivaron arroz, maíz y soya durante el semestre A 2019, para el Piedemonte específicamente en los municipios de Villavicencio, Granada y Fuente de Oro, y la Altillanura para los municipios de Puerto Lopez y Puerto Gaitán, localizados en la figura 1. 
Tabla 1. Variables cualitativas y categorías observadas en los predios encuestados

\begin{tabular}{|c|c|c|}
\hline Variables & Categorías & Código \\
\hline \multicolumn{3}{|l|}{ Sociales } \\
\hline \multirow{4}{*}{$\begin{array}{l}\text { Estado civil del } \\
\text { producto }\end{array}$} & Soltero & SOLTERO \\
\hline & Unión Libre & UNION \\
\hline & Casado & CASADO \\
\hline & Primaria & PRIM \\
\hline \multirow{3}{*}{ Nivel de escolaridad } & Bachillerato & $\mathrm{BACH}$ \\
\hline & Tecnológica & TECN \\
\hline & Profesional & PROF \\
\hline \multirow{2}{*}{ Afiliación a EPS } & No afiliado & NO_EPS \\
\hline & Sisbén & SISBEN \\
\hline \multirow{3}{*}{$\begin{array}{l}\text { Número de familiares } \\
\text { que habitan el predio }\end{array}$} & Ninguno & FAM_0 \\
\hline & Uno & FAM_1 \\
\hline & Dos & FAM_2 \\
\hline \multirow{2}{*}{$\begin{array}{l}\text { Tipo de tenencia } \\
\text { de la tierra }\end{array}$} & Propia & TEN_PRO \\
\hline & Arrendada & TEN_ARR \\
\hline \multirow{2}{*}{$\begin{array}{l}\text { La finca posee } \\
\text { alumbrado público }\end{array}$} & $\mathrm{Si}$ & ALU_S \\
\hline & No & ALU_N \\
\hline \multirow{2}{*}{$\begin{array}{l}\text { Estado de las vías } \\
\text { de acceso }\end{array}$} & Destapada & VIA_DES \\
\hline & Pavimentada & VIA_PAV \\
\hline \multirow{5}{*}{$\begin{array}{l}\text { Número de } \\
\text { trabajadores } \\
\text { permanentes }\end{array}$} & Ninguno & PER_O \\
\hline & Uno & PER_1 \\
\hline & Dos & PER_2 \\
\hline & Tres & PER_3 \\
\hline & Más de tres & PER_+3 \\
\hline \multirow{4}{*}{$\begin{array}{l}\text { Número de } \\
\text { trabajadores } \\
\text { temporales }\end{array}$} & Ninguno & TEM_0 \\
\hline & Uno & TEM_1 \\
\hline & Dos & TEM_2 \\
\hline & Más de dos & TEM_+2 \\
\hline \multicolumn{3}{|l|}{ Económicas } \\
\hline \multirow{2}{*}{$\begin{array}{l}\text { Utilización de recursos } \\
\text { propios para el } \\
\text { proceso productivo }\end{array}$} & $\mathrm{Si}$ & RECP_S \\
\hline & No & RECP_N \\
\hline \multirow{2}{*}{$\begin{array}{l}\text { Utilización de recursos } \\
\text { provenientes de una } \\
\text { casa comercia }\end{array}$} & $\mathrm{Si}$ & CACOM_S \\
\hline & No & CACOM_N \\
\hline \multicolumn{3}{|l|}{ Agronómicas } \\
\hline \multirow{3}{*}{$\begin{array}{l}\text { Cultivo predominante } \\
\text { en el proceso } \\
\text { productivo }\end{array}$} & Arroz & ARROZ \\
\hline & Maíz & MAIZ \\
\hline & Soya & SOYA \\
\hline \multirow{3}{*}{$\begin{array}{l}\text { Lugar donde vende } \\
\text { la cosecha }\end{array}$} & Comerciante & VEN_COM \\
\hline & Finca & VEN_FIN \\
\hline & Molino & VEN_MOL \\
\hline
\end{tabular}

\section{Análisis descriptivo}

Se obtuvieron de cada zona apreciaciones iniciales en cuanto a aspectos sociales y económicos. Los productores cuentan con un rango mínimo y máximo de edad entre 20 a 88 años en Piedemonte y 31 a 70 años para Altillanura, que presenta un promedio de edad mayor (51 años) que el Piedemonte. Sin embargo, estas edades no reflejan diferencias significativas con el tiempo utilizado para la producción de cultivos transitorios. Los agricultores de las dos zonas cuentan en promedio con la misma cantidad de años dedicados a estas actividades, ver figura 2 .

En cuanto al estado civil ambas zonas presentan más de la mitad de los agricultores con vínculos familiares, para el caso de la Altillanura se encuentran casados el $52 \%$ y en unión libre el $39 \%$ y para el Piedemonte los casados corresponden al $29 \%$ y en unión libre al $47 \%$, lo que refleja que los agricultores dedicados a esta actividad agrícola contribuyen de alguna forma al sostenimiento de un hogar. Con respecto a los solteros la mayor concentración se ubica en el Piedemonte $(24 \%)$ por contener a los productores más jóvenes. (ver figura 3).

En cuanto a las condiciones de educación, en general, las dos zonas presentan al menos la mitad de sus agricultores con nivel de educación primaria, ya para niveles superiores de escolaridad, la Altillanura cuenta con mayor cantidad de agricultores que son profesionales, mientras que en el Piedemonte los agricultores están más formados en carreras técnicas o tecnólogos, como se aprecia en la figura 4 (a). Esta relación puede darse porque en la Altillanura con sus grandes extensiones, requieren de persona más calificada que conozca sobre el sistema productivo, maquinarias de última generación y tecnologías avanzadas, y en el Piedemonte los agricultores se especializan en ciertos aspectos básicos del manejo de cultivos transitorios (plagas, enfermedades, malezas). Donde en ambas zonas predominan las labores de los hombres para el desarrollo de las actividades técnicas y tecnológicas.

Para las condiciones de salud, más del $85 \%$ de los agricultores en el Piedemonte y la Altillanura se encuentran vinculados con alguna empresa prestadora de salud (EPS) pública o privada, tal como se muestra en la figura 4 (b). Aunque por ley, se exige que toda persona vinculada a una entidad debe pagar salud incluso si son agricultores independientes, para que inviertan en su propia salud y mejoraren el bienestar personal y familiar, existe un porcentaje que no cumplen esta norma debido al intermitente ingreso de los productores (cada cosecha) y a la dispersión de los centros de atención de salud en esta extensa región. 


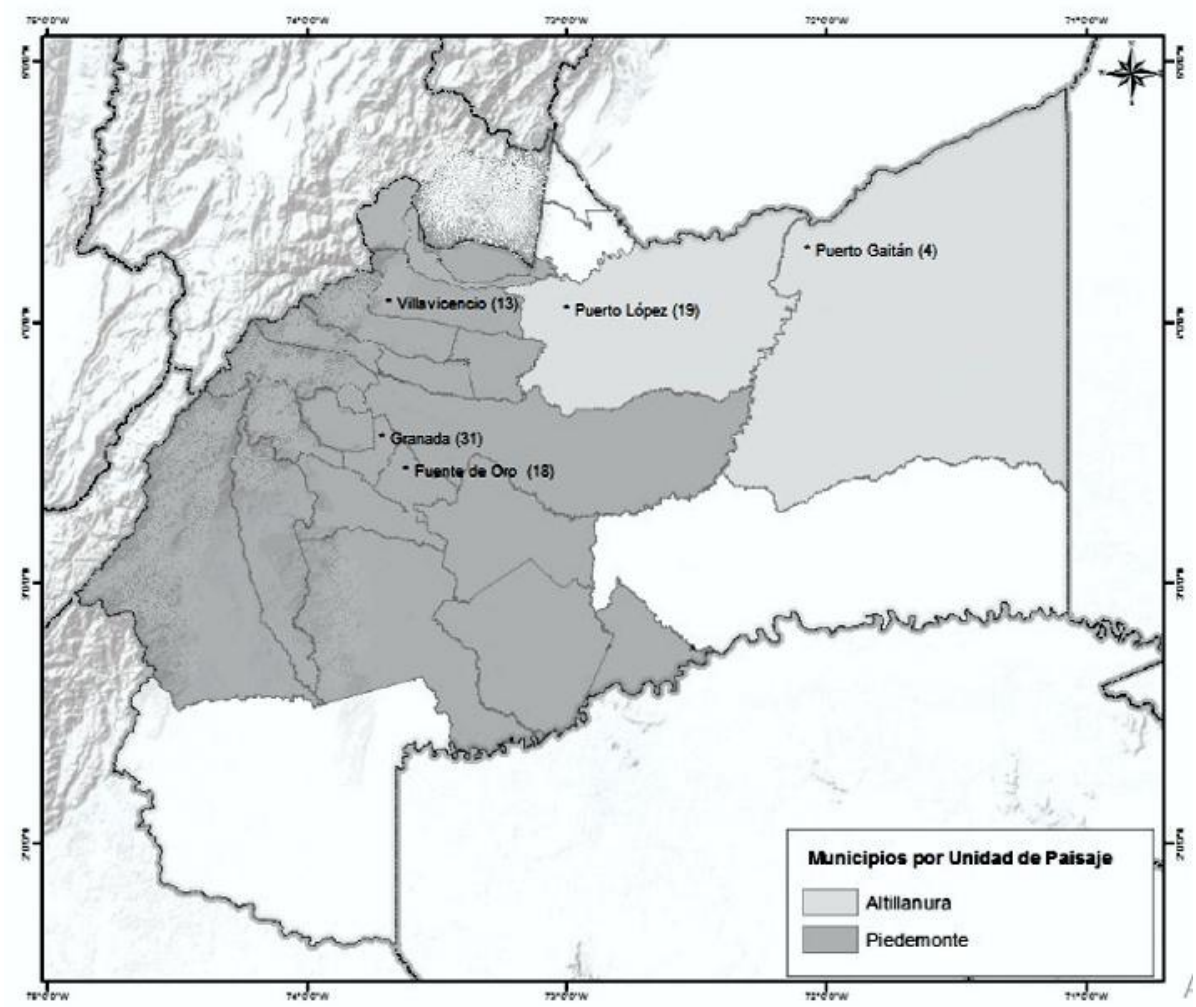

Figura 1. Municipios encuestados en el Piedemonte y la Altillanura, del departamento de Meta Fuente: Agrosavia

El sistema productivo está directamente asociado con el tipo de tenencia de tierra de los productores, es lógico identificar que para cultivos transitorios o de ciclo corto como los analizados en este estudio, predomine los agricultores con propiedades arrendadas (ver figura 5). Sin embargo, independientemente de la tenencia, los agricultores de Piedemonte poseen 42 fincas con alumbrado o energía eléctrica $(67 \%)$ ya que la mayoría habitan en ella, mejorando la calidad de vida y aprovechando su uso eléctrico para las diferentes actividades complementaria a la producción (motobom-

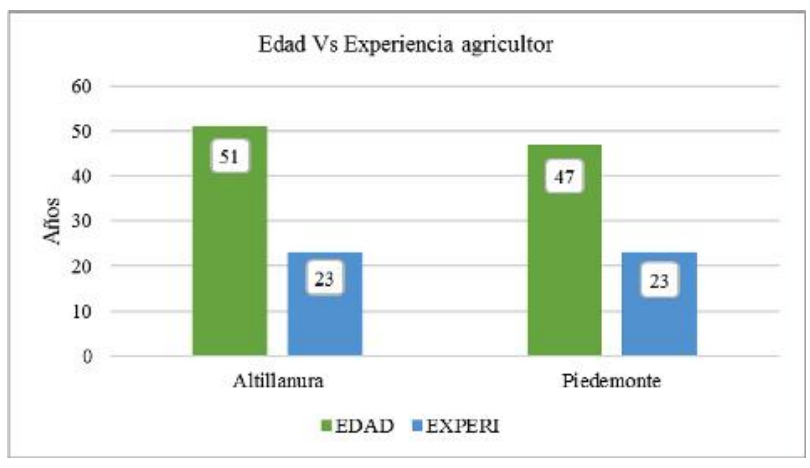

Figura 2. Edad promedio y experiencia (años) en el manejo de los cultivos de los agricultores en el Piedemonte y la AltiIlanura bas, desgranadoras, compresores), caso contrario en la Altillanura donde los predios son netamente para la producción por lo que no requieren de este servicio y solamente 10 predios indicaron que si poseen (43\%).

El estado de las vías influye directamente en las condiciones del agricultor, desde el tiempo que tardan en desplazarse al predio, la disponibilidad del transporte por la falta o dificultad en el acceso, hasta los costos para transportar los insumos y las cosechas, porque deben usar mayor cantidad de combustible, realizar continuamente mantenimientos a los vehículos, entre otros aspectos. La figura 6 muestra que las fincas de los productores en la Altillanura cuentan con solo el $17 \%$ de las vías pavimentadas por ser las rutas de principal acceso (Puerto Gaitán y Vichada), mientras que en el Piedemonte más de la mitad de las vías se encuentran pavimentadas (52\%). En las dos zonas existe un porcentaje significativamente alto de fincas que no cuenta con vías pavimentadas, en la Altillanura se debe a las grandes extensiones que las conforman y en el Piedemonte por su proximidad a las vías principales ocasionan que las vías secundarias donde se encuentran la mayoría de los agricultores no sean priorizadas para la pavimentación.

En la figura 7, se evidencia que en la Altillanura existen predios de mayor extensión. Específicamente, en 

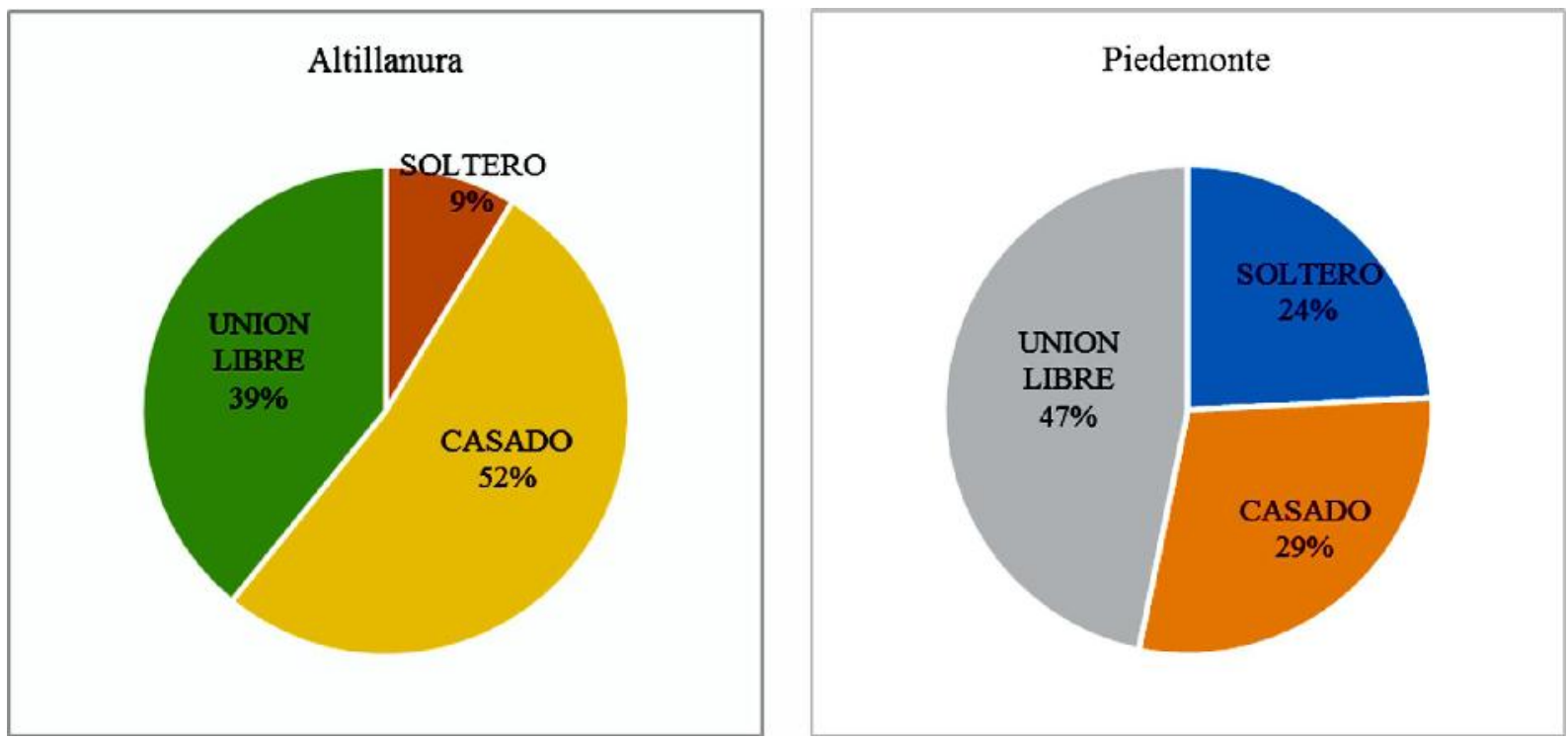

Figura 3. Estado civil de los agricultores en el Piedemonte y Altillanura
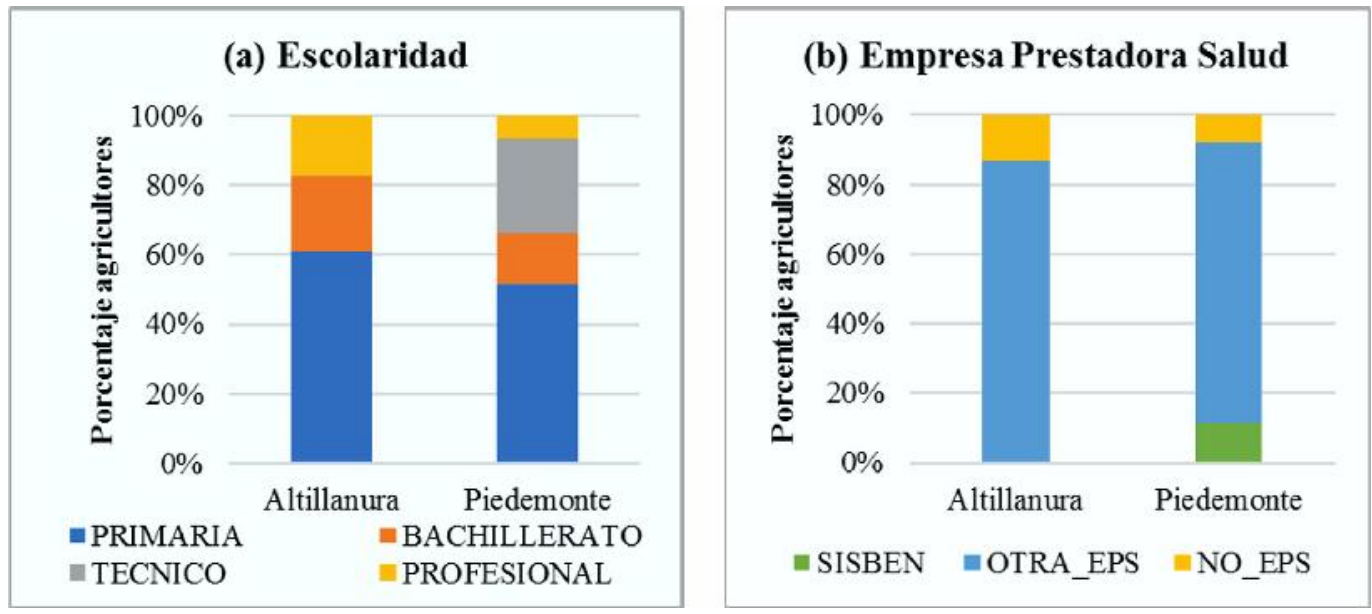

Figura 4. (a) Escolaridad y (b) sistema de salud de los agricultores en el Piedemonte y Altillanura

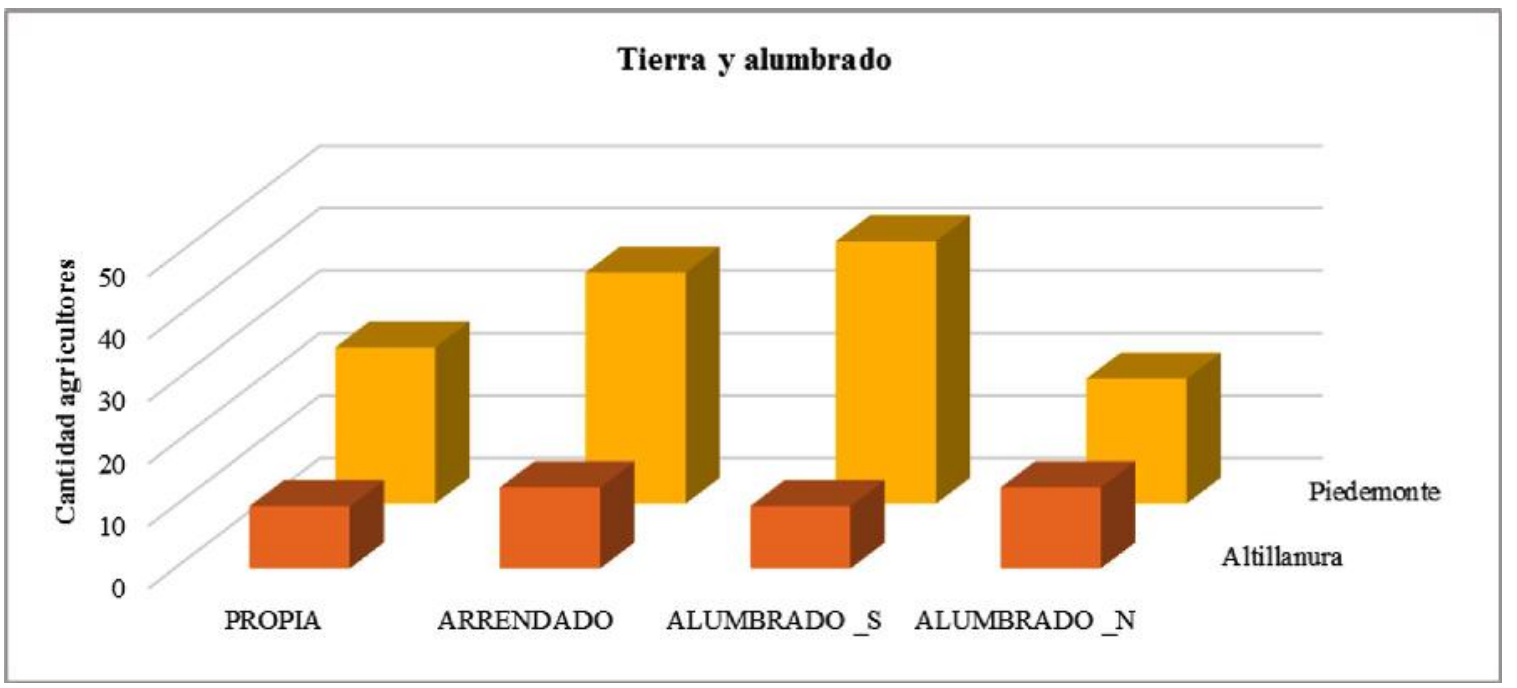

Figura 5. Tenencia y alumbrado de las tierras de los agricultores en el Piedemonte y Altillanura 

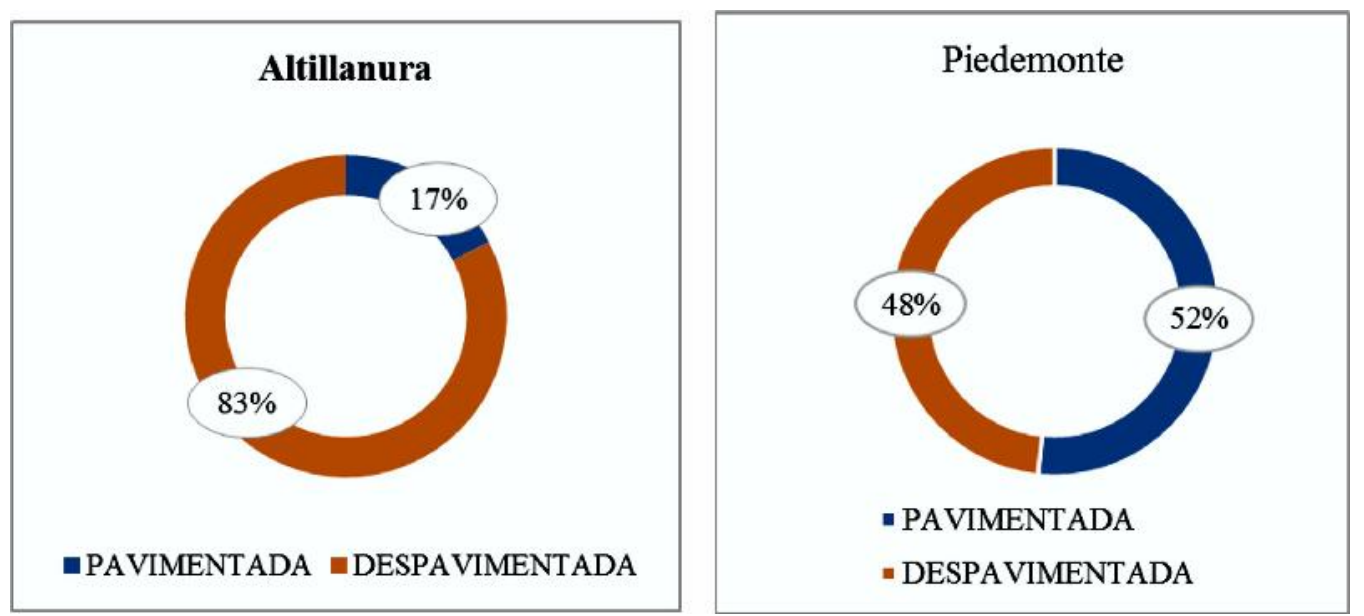

Figura 6. Estado de las vías en los predios de los agricultores en el Piedemonte y Altillanura

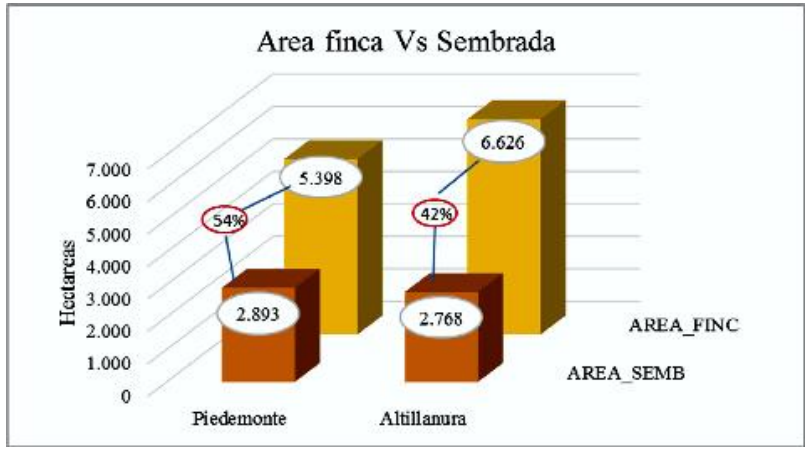

Figura 7. Áreas de predios y sembrada en cultivos transitorios para el Piedemonte y Altillanura

las áreas destinadas para cultivos transitorios el 54\% y $42 \%$ del área total de las fincas desarrollan esta actividad en el Piedemonte y la Altillanura, respectivamente.

En términos productivos, para el primer semestre del 2019, los agricultores del Piedemonte siembran sobre todo maíz seguido por soya y arroz, y realizan la venta en molinos por ser establecimientos seguros y reconocidos por los compradores. En cuanto a los agricultores de la Altillanura, se concentran más en la siembra de arroz, seguido de maíz y soya, y venden a intermediarios o comercializadores de la zona (ver figura 8 (a) y (b)).

Los cultivos de ciclo corto son generadores de empleo de tipo temporal, permanente y familiar. El comportamiento de las dos zonas conserva una preferencia por contratar a personal externo (temporal y permanente) de la finca para desarrollar sus actividades, como se evidencia en la figura 9. Cabe resaltar que, aunque la participación de la familia en la actividad es baja, la principal causa es la migración de la descendencia de los agricultores en búsqueda de mejores oportunidades a centros urbanos cercanos, aunque algunos de ellos conservan la tradición familiar. La brecha de la mano de obra entre la Altillanura y Piedemonte se da
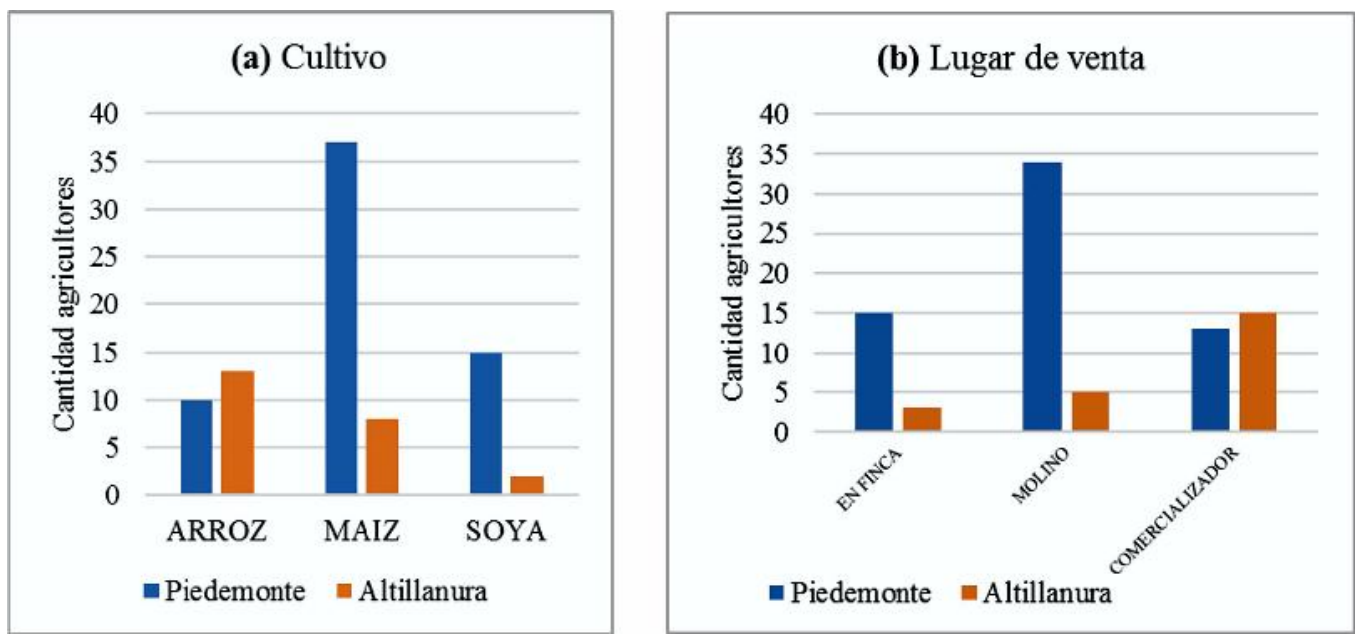

Figura 8. (a) Cultivo transitorio predominante y (b) lugar de venta de los agricultores del Piedemonte y Altillanura 


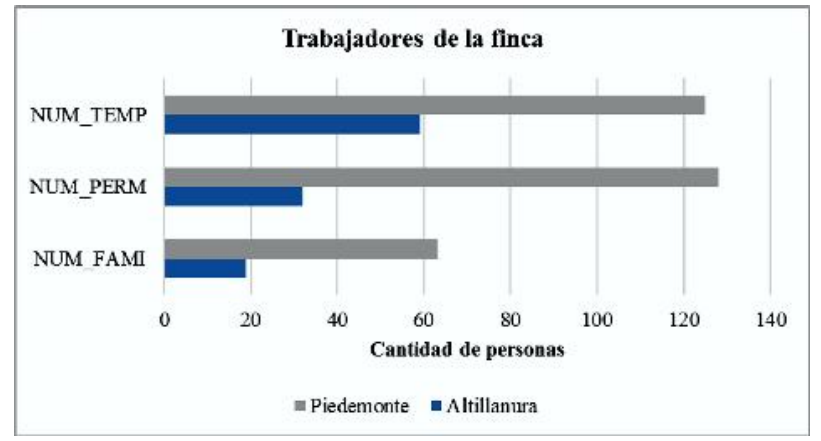

Figura 9. Cantidad de trabajadores en las fincas del Piedemonte y Altillanura

por la tecnología existente en cada zona, dado que la primera utiliza maquinarias y equipos con tecnologías de última generación requiriendo menor mano de obra y en la segunda manejan mayor cantidad de personal por tener otro tipo de tecnologías menos avanzadas.

Los agricultores del Piedemonte tienen en promedio unos ingresos semestrales como producto de la actividad agrícola de $\$ 418.000$ por hectárea, valores mayores que en la Altillanura, cuyos ingresos son alrededor de $\$ 370.000$ por hectárea, esto se debe a una mejor ubicación geográfica, mayores compradores de grano (arroz, maíz o soya), menores costos de transporte por las condiciones de las vías, entre otros.

En general, los agricultores utilizan diferentes fuentes de financiamiento para apalancar sus cultivos, mientras las cosechas, en algunos casos utilizan 2 o más alternativas (cooperativas, bancas privadas o públicas). Las fuentes más utilizadas en las dos zonas son las casas comerciales, ya que no solo le suministran los insumos (semilla, fertilizantes, fungicidas, herbicidas) a crédito, sino que les brindan asesorías técnicas acordes a las necesidades del cultivo (Figura 10).

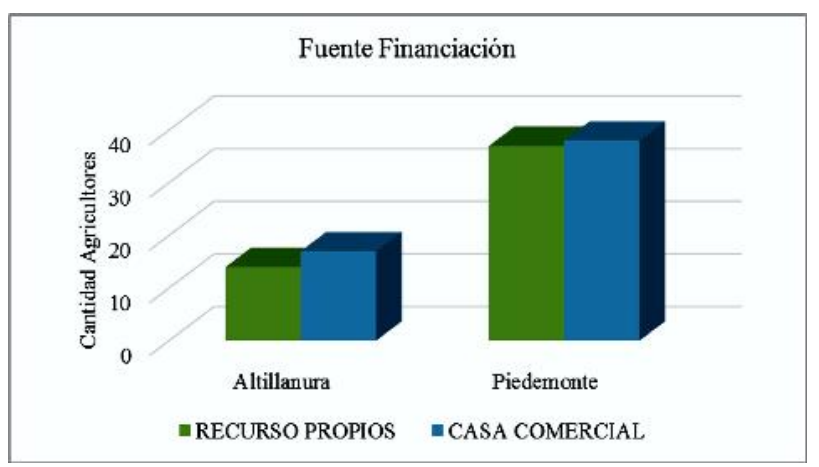

Figura 10. Fuentes de financiación de los agricultores del Piedemonte y Altillanura

\section{Determinación de tipos o subsistemas.}

El análisis de correspondencia múltiple permitió seleccionar los primeros siete factores que acumularon el $49.4 \%$ de la variabilidad contenida en el conjunto de datos original. En la tabla 2, se exponen los valores propios correspondientes a cada uno de los factores generados con su respectiva contribución en la explicación de la variabilidad del conjunto de datos original.

Tabla 2. Valores propios correspondientes a cada factor generado del análisis de correspondencia múltiple

\begin{tabular}{|c|c|c|}
\hline Valores propios & $\%$ & $\%$ acumulado \\
\hline 0.44898 & 10.45 & 10.45 \\
\hline 0.38244 & 7.58 & 18.04 \\
\hline 0.37168 & 7.16 & 25.20 \\
\hline 0.35758 & 6.63 & 31.83 \\
\hline 0.34821 & 6.29 & 38.12 \\
\hline 0.34535 & 6.18 & 44.30 \\
\hline 0.31448 & 5.13 & 49.43 \\
\hline 0.29957 & 4.65 & 54.08 \\
\hline 0.29391 & 4.48 & 58.56 \\
\hline 0.28334 & 4.16 & 62.72 \\
\hline 0.27533 & 3.93 & 66.65 \\
\hline 0.26814 & 3.73 & 70.38 \\
\hline 0.25933 & 3.49 & 73.87 \\
\hline 0.25074 & 3.26 & 77.13 \\
\hline 0.24026 & 2.99 & 80.12 \\
\hline 0.23257 & 2.80 & 82.93 \\
\hline 0.22168 & 2.55 & 85.48 \\
\hline 0.21492 & 2.40 & 87.87 \\
\hline 0.20871 & 2.26 & 90.13 \\
\hline 0.19313 & 1.93 & 92.06 \\
\hline 0.18157 & 1.71 & 93.77 \\
\hline 0.16974 & 1.49 & 95.27 \\
\hline 0.15961 & 1.32 & 96.59 \\
\hline 0.14655 & 1.11 & 97.70 \\
\hline 0.13904 & 1.00 & 98.70 \\
\hline 0.12101 & 0.76 & 99.46 \\
\hline 0.10174 & 0.54 & 100.00 \\
\hline
\end{tabular}

Con base en los siete factores seleccionados, se realizó el análisis de conglomerados que permitió obtener cinco grupos de predios homogéneos, para las variables socioeconómicas de tipo categórico. En la figura 


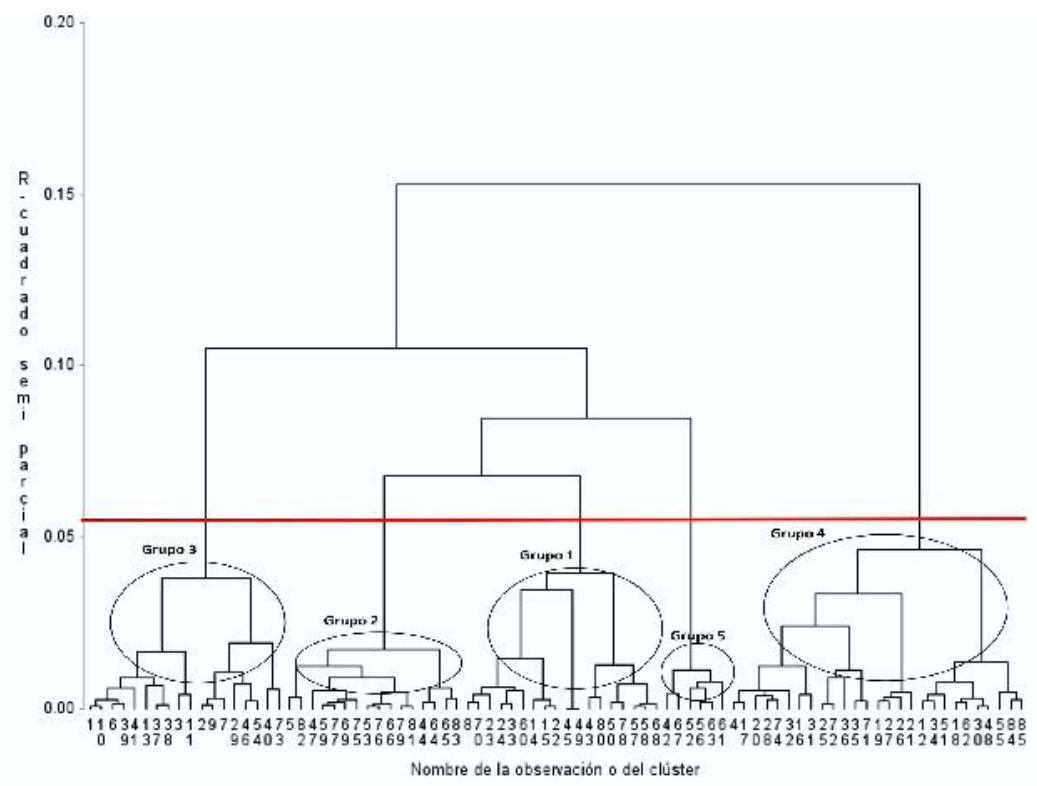

Figura 11. Dendrograma correspondiente al agrupamiento de los predios encuestados

11, se expone el dendrograma obtenido con base en el análisis anteriormente mencionado. La línea horizontal ilustra la distancia a la cual se conformaron los grupos de predios.

En la tabla 3, se presenta la conformación de los grupos de predios que fue realizada con base en el análisis de conglomerados. Estos grupos serán caracterizados y tipificados más adelante.

Tabla 3. Conformación de los grupos de predios, de acuerdo con el análisis de conglomerados

\begin{tabular}{|c|c|c|}
\hline Grupos & $\begin{array}{c}\text { Número de predios } \\
\text { incluidos en cada grupo }\end{array}$ & $\mathbf{\%}$ \\
\hline 1 & 18 & 21.2 \\
\hline 2 & 16 & 18.8 \\
\hline 3 & 18 & 21.2 \\
\hline 4 & 27 & 31.8 \\
\hline 5 & 6 & 7.0 \\
\hline Total & 85 & 100 \\
\hline
\end{tabular}

Para facilitar la descripción y posterior tipificación de los grupos de predios, se generaron tablas de frecuencia de cada grupo por variable. En la tabla 4, se pueden observar los valores relativos para cada categoría de las variables en los diferentes grupos.

En las tablas 4 y 5, se relacionan las estadísticas (medias por grupos y general), que permitieron describir las características de cada uno de los grupos conformados mediante el análisis de conglomerados

\section{Descripción de los tipos o grupos}

A continuación, se plantean las tipologías y las características más relevantes de los diferentes grupos de productores que se conformaron, con base en el análisis de conglomerados (Tablas 4 y 5 ).

Grupo 1. Productores mayormente maiceros: Es la segunda agrupación con el mayor número de predios en arriendo y con vías pavimentadas, pero también son el segundo grupo en cuanto a la cantidad de predios que no poseen alumbrado eléctrico. La edad promedio de los productores es de 49 años, superior a la media general, gran parte de los productores pertenecientes a este grupo $(89 \%)$ están vinculados a EPS privadas y es el que posee más cantidad de profesionales. Se dedican completamente a la producción de maíz, y casi la totalidad de la cosecha la venden en la finca (94\%). Utiliza mano de obra familiar que predomina sobre otros tipos de categorías de trabajadores (Salgar, 2004). Económicamente, son los que poseen los ingresos más altos y con medios propios de financiación principalmente. A este grupo pertenece agricultores pioneros de la Altillanura que presentan una alta organización técnica y administrativa (DNP, 2018). Aunque el $67 \%$ de los encuestados están concentrados principalmente en el Piedemonte llanero y el $33 \%$ en la Altillanura, pertenecientes a los municipios de Villavicencio (1), Granada (7), Fuente de oro (4), Puerto López (5), Puerto Gaitán (1). 
Tabla 4. Participación de los predios por categoría para las variables cualitativas

\begin{tabular}{|c|c|c|c|c|c|c|}
\hline \multirow{2}{*}{ Variables } & \multirow{2}{*}{ Categorías } & \multicolumn{5}{|c|}{ Grupos } \\
\hline & & 1 & 2 & 3 & 4 & 5 \\
\hline \multirow{4}{*}{ Nivel de escolaridad } & Primaria & 38.89 & 50.00 & 61.11 & 62.96 & 50.00 \\
\hline & Bachillerato & 5.56 & 25.00 & 16.67 & 14.81 & 33.33 \\
\hline & Tecnología & 11.11 & 00.00 & 11.11 & 0.00 & 0.00 \\
\hline & Profesional & 44.44 & 25.00 & 11.11 & 22.22 & 16.67 \\
\hline \multirow{2}{*}{$\begin{array}{l}\text { Utilización de recursos propios } \\
\text { para el proceso productivo }\end{array}$} & $\mathrm{Si}$ & 72.22 & 25.00 & 66.67 & 59.26 & 100.00 \\
\hline & $\mathrm{No}$ & 27.78 & 75.00 & 33.33 & 40.74 & 0.00 \\
\hline \multirow{3}{*}{ Afiliación a EPS } & No afiliado & 11.11 & 6.25 & 0.00 & 18.52 & 0.00 \\
\hline & SISBEN & 0.00 & 6.25 & 0.00 & 0.00 & 100.00 \\
\hline & Otra EPS & 88.89 & 87.50 & 100.00 & 81.48 & 0.00 \\
\hline \multirow{2}{*}{$\begin{array}{l}\text { Utilización de recursos provenientes } \\
\text { de una casa comercial }\end{array}$} & $\mathrm{Si}$ & 16.67 & 100.00 & 61.11 & 85.19 & 33.33 \\
\hline & No & 83.33 & 0.00 & 38.89 & 14.81 & 66.67 \\
\hline \multirow{3}{*}{ Estado civil del productor } & Soltero & 22.22 & 25.00 & 27.78 & 14.81 & 0.00 \\
\hline & Unión Libre & 33.33 & 75.00 & 33.33 & 37.04 & 66.67 \\
\hline & Casado & 44.44 & 0.00 & 38.89 & 48.15 & 33.33 \\
\hline \multirow{3}{*}{$\begin{array}{l}\text { Cultivo predominante en el } \\
\text { proceso productivo }\end{array}$} & Arroz & 0.00 & 0.00 & 0.00 & 77.78 & 33.33 \\
\hline & Maíz & 100.00 & 93.75 & 27.78 & 11.11 & 66.67 \\
\hline & Soya & 0.00 & 6.25 & 72.22 & 11.11 & 0.00 \\
\hline \multirow{4}{*}{ Número de familiares que habitan el predio } & Ninguno & 22.22 & 81.25 & 50.00 & 62.96 & 33.33 \\
\hline & Uno & 61.11 & 6.25 & 16.67 & 11.11 & 16.67 \\
\hline & Dos & 0.00 & 6.25 & 5.56 & 18.52 & 50.00 \\
\hline & Más de dos & 16.67 & 6.25 & 27.78 & 7.41 & 0.00 \\
\hline \multirow{5}{*}{ Número de trabajadores permanentes } & Ninguno & 72.22 & 37.50 & 27.78 & 40.74 & 83.33 \\
\hline & Uno & 5.56 & 0.00 & 0.00 & 22.22 & 0.00 \\
\hline & Dos & 0.00 & 6.25 & 38.89 & 11.11 & 0.00 \\
\hline & Tres & 16.67 & 0.00 & 11.11 & 14.81 & 16.67 \\
\hline & Más de tres & 5.56 & 56.25 & 22.22 & 11.11 & 0.00 \\
\hline \multirow{4}{*}{ Número de trabajadores temporales } & Ninguno & 66.67 & 56.25 & 38.89 & 37.04 & 16.67 \\
\hline & Uno & 11.11 & 6.25 & 22.22 & 3.70 & 16.67 \\
\hline & Dos & 0.00 & 6.25 & 22.22 & 11.11 & 66.67 \\
\hline & Más de dos & 22.22 & 31.25 & 16.67 & 48.15 & 0.00 \\
\hline \multirow{3}{*}{ Lugar donde vende la cosecha } & Comerciante & 0.00 & 6.25 & 77.78 & 7.41 & 16.67 \\
\hline & Finca & 94.44 & 87.50 & 16.67 & 7.41 & 50.00 \\
\hline & Molino & 5.56 & 6.25 & 5.56 & 85.19 & 33.33 \\
\hline \multirow{2}{*}{ Tipo de tenencia de la tierra } & Arrendada & 66.67 & 56.25 & 50.00 & 59.26 & 66.67 \\
\hline & Propia & 33.33 & 43.75 & 50.00 & 40.74 & 33.33 \\
\hline \multirow{2}{*}{ La finca posee alumbrado público } & $\mathrm{Si}$ & 61.11 & 68.75 & 66.67 & 51.85 & 66.67 \\
\hline & No & 38.89 & 31.25 & 33.33 & 48.15 & 33.33 \\
\hline \multirow{2}{*}{ Estado de las vías de acceso } & Destapada & 38.89 & 31.25 & 61.11 & 81.48 & 66.67 \\
\hline & Pavimentada & 61.11 & 68.75 & 38.89 & 18.52 & 33.33 \\
\hline
\end{tabular}

Tabla 5. Valores medios de las variables cuantitativas para los grupos conformados

\begin{tabular}{|l|c|c|c|c|c|c|c|}
\hline \multicolumn{1}{|c|}{ Variables } & Unidad & $\begin{array}{c}\text { Grupo 1 } \\
(\mathbf{n = 1 8})\end{array}$ & $\begin{array}{c}\text { Grupo 2 } \\
(\mathbf{n = 1 6})\end{array}$ & $\begin{array}{c}\text { Grupo 3 } \\
(\mathbf{n = 1 8})\end{array}$ & $\begin{array}{c}\text { Grupo 4 } \\
(\mathbf{n = 2 7})\end{array}$ & $\begin{array}{c}\text { Grupo 5 } \\
(\mathbf{n = 6})\end{array}$ & $\begin{array}{c}\text { Media } \\
\text { General }\end{array}$ \\
\hline Edad & años & $\mathbf{4 9}$ & 47 & $\mathbf{5 0}$ & $\mathbf{4 9}$ & 42 & 48 \\
\hline Experiencia & años & 21 & 23 & $\mathbf{2 5}$ & $\mathbf{2 4}$ & 22 & 23 \\
\hline Área finca & has & 54 & 74 & 118 & $\mathbf{3 0 0}$ & 10 & 147 \\
\hline Área sembrada & has & 19 & 51 & $\mathbf{8 2}$ & $\mathbf{1 1 0}$ & 9 & 67 \\
\hline Ingreso & pesos & $\mathbf{6 0 6 . 1 5 0}$ & $\mathbf{4 1 6 . 4 5 8}$ & 222.493 & 370.550 & $\mathbf{5 1 5 . 2 4 1}$ & 406.467 \\
\hline
\end{tabular}


Grupo 2. Productores maiceros y soyeros: En este grupo el $56 \%$ de los productores son arrendatarios, con más de la mitad de los predios con servicio de alumbrado eléctrico y mayores vías pavimentadas. Los productores se encuentran mayormente en condición de unión libre y cuentan sobre todo con EPS privadas. La actividad económica radica esencialmente en el maíz, pero se cultiva también soya, el lugar de venta de la cosecha es en la propia finca. La mano de obra usualmente contratada es permanente en comparación con las otras categorías. Los ingresos del semestre son mayores al de la media general y emplea como fuente de financiación para sus siembras las casas comerciales. Todos los productores encuestados están ubicados en el Piedemonte llanero, en los municipios de Villavicencio (1), Granada (7) y Fuente de oro (8).

Grupo 3. Productores principalmente soyeros: Los productores pertenecientes a este grupo cuentan con el $50 \%$ de predios propios y más de la mitad tienen alumbrado eléctrico $(66,6 \%)$, no obstante, son el segundo grupo con predios que poseen vías sin pavimentar. Es el grupo con mayor edad en promedio del productor (50 años) y el que presenta mayor experiencia en la actividad agrícola, todos se encuentran vinculados a EPS privadas. Su formación corresponde principalmente a educación primaria $(61,1 \%)$. Se dedican especialmente a la producción de soya (72\%) con áreas de siembras superiores en gran medida a la media general (82 ha), la venta se realiza sobre todo mediante comercializadores. Utilizan principalmente mano de obra permanente. Los ingresos semestrales son los más bajos debido a los problemas de competitividad (Corpoica, 2006), a su vez utilizan las dos fuentes de financiación (recursos propios y casas comerciales) para sus cultivos. Estos productores están localizados principalmente en el Piedemonte llanero (94\%), en los municipios de Villavicencio (9), Granada (7), Fuente de oro (1) y Puerto López (1).

Grupo 4. Productores principalmente arroceros: Este grupo es el más numeroso, el $59 \%$ de los predios se explotan bajo la modalidad de arriendo (ASIALL, 2019), con casi la mitad de los predios sin servicio de alumbrado eléctrico y con mayores vías sin pavimentar. El productor promedio tiene una edad de 49 años con experiencia de 24 años en la actividad, superando el promedio general. Casi la mitad de los productores, son casados. Gran parte de ellos, están vinculados a una EPS privada pese a que es el grupo con el mayor número de productores, que no cuentan con EPS. La formación educativa del productor es sobre todo en primaria $(63 \%)$, a pesar de que existen productores con niveles de bachillerato y profesional. La dedicación fundamental está en el cultivo de arroz (77\%), es el grupo con áreas de fincas y de siembra más grandes, que la media general. La venta del grano se realiza en su mayoría a los molinos. Con respecto a la mano de obra, la más manejada es la temporal. La fuente de financiación proviene de recursos propios y casas comerciales, mayormente la segunda (Fedearroz, 2011). En cuanto a los productores encuestados el 59\% están situados en la Altillanura y la otra parte en el Piedemonte $(41 \%)$, específicamente en los municipios de Villavicencio (2), Granada (4), Fuente de oro (5), Puerto López (13), Puerto Gaitán (3).

Grupo 5. Productores maiceros y arroceros: Estos productores son el grupo más pequeño en predios, el $66,7 \%$ de estos son propiedades bajo la modalidad de arrendamiento, donde más de la mitad de estos cuentan con servicio de alumbrado eléctrico pero menores en vías pavimentadas (67\%). En cuanto a los productores su condición de estado civil está entre casados y unión libre, además todos se encuentran vinculados a EPS pública (Sisbén). Este grupo se dedica a cultivar sobre todo maíz, pero siembran además arroz. Utilizan mano de obra temporal. Los ingresos son los segundos más altos con base en la media general y emplea las dos fuentes de financiación para sus siembras con una tendencia hacia el uso de recursos propios. Estos productores solo se encuentran localizados en el municipio de Granada (6).

\section{Discusión}

Estas tipologías son similares al comportamiento nacional y regional de los productores agropecuarios, que de acuerdo con el 3er Censo Nacional evidencian la existencia de 43 millones de hectáreas en área rural destinada al uso agropecuario, de los cuales $4.8 \mathrm{mi}-$ llones de hectáreas corresponde al departamento del Meta, que se caracteriza por su economía agropecuaria al ser el proveedor más importante de alimentos básicos para la capital del país (Posada, 2016). A su vez, en el Meta se identificaron 30.000 predios o Unidad de producción agricola (UPA) con menos de 5 hectareas que abarcan 35.349 hectareas del area censada (ADR, 2019) parecido a la zona del Piedemonte que cuenta con mayor cantidad de productores o UPA en áreas pequeñas. Las grandes extensiones en el Meta (6.222.291 hectáreas) se encuentran en propiedad de 1.134 (ADR, 2019), semejantes a las observadas en los cultivos transitarios de la Altillanura donde se ubican pocos productores con áreas grandes.

A nivel nacional, los productores se encuentran en un rango de edad entre 55 a 59 años (DANE, 2017), cercanas a las edades promedios obtenidas en el Piedemonte (51 años) y la Altillanura (47 años), reflejando 
que los agricultores más adultos se dedican a estas actividades. El nivel de escolaridad de los productores en Colombia está mayormente concentrado en la educación básica primaria $(65,2 \%)$ (DANE, 2017) al igual que en las regiones estudiadas (52\% Piedemonte y $60 \%$ Altillanura), fundamentada por el hecho en que su nivel de educación le es suficiente para desarrollar las actividades necesarias en los cultivos transitorios.

En Colombia se cuenta con 4,5 millones de trabajadores permanentes en las Unidades de producción agrícolas y 6,5 millones de jornales adicionales contratados (DANE, 2014), situación que se asemeja al tipo de mano de obra que más contratan los productores encuestado del Piedemonte y la Altillanura, los cuales son temporales ( 125 y 59 trabajadores, respectivamente) y permanentes (128 y 32 empleados, respectivamente), aunque con baja participación de trabajadores familiares (63 y 19 miembros, respectivamente) por la migración de las nuevas generaciones en búsqueda de mejores alternativas.

Un aspecto para resaltar es el sistema de salud nacional, en el que más del 95,8\% de los productores residentes en el área rural se encuentran vinculados a algún tipo de sistema de Seguridad Social en Salud ya sea subsidiado (85\%), contributivo (14\%) o especial (1\%) (DANE, 2014), al igual que en el Piedemonte y Altillanura donde el 85\% de ellos cuentan con algún tipo de vinculación a empresas de salud privada (80\% Piedemonte, $87 \%$ Altillanura) o pública ( $11 \%$ Piedemonte) para así prevenir afectaciones en la salud y mejorar el bienestar.

En cuanto a la tenencia de la tierra en Colombia, el $72,7 \%$ de las Unidades de producción agrícolas son de tipo propio, seguido por las de arriendo (9,6\%) (DANE, 2014), caso contrario en las fincas de cultivos transitorios de las regiones de Piedemonte y Altillanura donde la condición propia es del $40 \%$ y $48 \%$, respectivamente y la de mayor predominancia son las arrendadas $(60 \%$ - $52 \%$, respectivamente) a causa que son cultivos de ciclo corto y no requieren de altas inversiones previas a la siembra que ameriten la compra de terreno.

La cobertura nacional con el servicio de energía eléctrica es del 32,8\% en las Unidades de producción agrícolas que indicaron su uso para el desarrollo de actividades agropecuarias (DANE, 2014) y mejoramiento en las condiciones de vida, al igual como se evidencio en los productores de Piedemonte y Altillanura (67\% y $43 \%$ respectivamente) que contaban con alumbrado eléctrico. Actualmente, existen proyectos de gobierno para generar redes eléctricas rurales en los municipios de Puerto López $(12,73 \mathrm{~km})$, Granada $(15,24 \mathrm{Km})$ y San Martin (5,26 Km) (Amaya, 2017).
Con respecto a la financiación, para el 2013 en Colombia el $6.4 \%$ de los productores en zona rural utilizó créditos (casas comerciales) para el desarrollo de las labores agropecuarias destinados principalmente a la compra de insumos (36.3\%) y pago de jornales (14.8\%) (DANE, 2015), motivos similares a los expuestos en las regiones de estudio, así: en Piedemonte $60 \%$ (38 agricultores) y Altillanura 70\% (17 agricultores).

La red de carreteras en el Meta correspondientes a las vías de orden nacional (911 km), se encuentran en un $47 \%(431 \mathrm{Km})$ pavimentadas y $53 \%(480 \mathrm{Km})$ des pavimentadas (González, 2004), tal como ocurren en las vías de la región del Piedemonte donde hay mayores productores ubicados en fincas con vías des pavimentadas $(52 \%)$ pero otro porcentaje significativo (48\%) localizado sobre vías pavimentadas. En cuanto a la Altillanura, el eje vial principal de esta región es la vía Bogotá - Puerto Carreño la cual se encuentra pavimentada hasta Puerto Gaitán y luego continua des pavimentada hasta finalizar en la capital del Vichada (Viloria, 2009), tal como sucede con los predios de los productores encuestados de cultivos transitorios donde el 83\% están localizados sobre vías des pavimentadas.

\section{Conclusión}

El comportamiento de los productores en el Piedemonte y la Altillanura del primero semestre del 2019 conservan la característica de orientar las siembras en cultivos transitorios de arroz, maíz y soya, ubicados sobre todo en áreas más pequeñas del Piedemonte que en la Altillanura.

Para este periodo, se identificaron diferentes tipos de productores, los que sembraron sobre todo maíz (grupo 1), los sembradores de maíz y soya (grupo 2), los dedicados mayormente a soya (grupo 3), los agricultores principalmente arroceros (grupo 4) y por último, los maiceros y soyeros (grupo 5).

De acuerdo a los resultados obtenidos en las agrupaciones permiten que los entes territoriales tomen decisiones más certeras para el mejoramiento de las políticas de bienestar de los productores de cultivos transitorios ya sea en salud, educación, derecho a pensión, vivienda, servicios públicos, entre otros.

En términos generales, se identifican no solo las características socioeconómicas del productor sino también las principales falencias que se presentan en el sistema productivo, como por ejemplo, que una de las dificultades para los productores mayormente maiceros (grupo 1) es la falta de relevo ge- 
neracional ya que se encuentran en una edad en promedio de 49 años donde sus rendimientos productivos tienden a ser decrecientes. Con relación a los productores maiceros y soyeros (grupo 2) la participación activa de las casas comerciales quienes prestan servicios de comercialización buscan más un beneficio económico directo, que un adecuado acompañamiento técnico. Para los productores mayormente soyeros (grupo 3) el problema radica en los bajos precios de compra semestrales del grano, debido a que por años los precios de compra han permanecido constantes, sin tener en cuenta que los costos de producción se han incrementado, favoreciendo las importaciones lo que genera mayor competencia perjudicando directamente los ingresos del productor. Con respecto a los productores mayormente arroceros (grupo 4) su limitación principal es el estado deficiente de las vías, lo que dificulta la entrada de insumos, mano de obra y maquinarias a los predios, y a su vez, a la salida del producto a los lugares de venta. Por último, con los productores maiceros y arroceros (grupo 5) se cuestiona el uso de la mano de obra temporal que, aunque es una alternativa laboral para la región, se pierda tiempo en volver a capacitar al nuevo personal, para realizar los manejos adecuados de los cultivos y el uso eficiente de las maquinarias y equipos.

\section{Agradecimientos}

Los autores expresan su agradecimiento al Ministerio de Agricultura y Desarrollo Rural (MADR) por la financiación de este proyecto.

Así mismo, a los investigadores Elsa Judith Guevara Agudelo, Nathali López Cardona, Jaime Humberto Bernal Riobo y a la profesora Clara Inés Caro Caro de la Universidad de los Llanos por las contribuciones de sus conocimientos en el sistema productivo y la región de estudio.

\section{Referencias}

ADR. (2019). Plan integral de desarrollo Agropecuario y rural con enfoque territorial, departamento del Meta. Agencia de desarrollo Rural y el Ministerio de Agricultura y desarrollo rural.

Amaya M. (2017). Informe técnico de gestión del departamento administrativo de planeación del departamento del Meta.

Asociación Ingeniero agrónomos del Llano. (2019). Revista ASIALL. Edición 40. Pag 14.

Calderón JC, Astudillo M, Romero MH. Caracterización epidemiológica de la infección por Leptospira spp. en caballos de trabajo y en personal ocupacionalmente expuestas en seis unidades de la policía nacional de Colombia. Biomédica, 2019;39:19-34.
Corpoica. (1999). Caracterización de los sistemas de producción agropecuarios en los municipios de Granada y Cumaral Meta, dando a conocer variables del componente socioeconómico y Biofísicas. Informe técnico $\mathrm{N}^{\circ} 11$. Villavicencio, Meta, Colombia.

Corpoica. (2006). Soya, alternativas para los sistemas de producción de la Orinoquia Colombiana. Villavicencio - Meta. Pag 70

DANE. (2014). $3^{\circ}$ Censo Nacional Agropecuaria. Tomo 2 Resultados.

DANE. (2015). $3^{\circ}$ Censo Nacional Agropecuaria. Caracterización de los productores residentes en el área rural dispersa censada.

DANE. (2017). Encuesta Nacional Agropecuaria 2017. Boletín técnico.

DNP. (2018). Modelo de Ordenamiento territorial de la Orinoquia: Fase de diagnóstico. Pag 108.

Escobar G, Berdegué J. (1990). Tipificación de sistemas de producción agrícola. Red Internacional de Metodología de Investigación de Sistemas de Producción (RIMISP). Santiago de Chile.

FAO. (2011). "RESUMEN-El estado de los recursos de tierras y aguas del mundo para la alimentación y la agricultura. Cómo gestionar los sistemas en peligro" Roma, Organización de las Naciones Unidas para la Alimentación y la Agricultura.

Fedearroz. (2010). Evaluación socioeconómica de la cadena productiva del arroz en Colombia. Bogotá, Colombia.

Fedearroz. (2011). Dinámica del sector arrocero de los llanos orientales de Colombia 1999 - 2011. Bogotá, Colombia.

Fedearroz. (2018). Producción de Arroz Paddy seco en Colombia por zonas. Estadísticas arroceras. URL: http://www.fedearroz. com.co/new/apr_public.php

Fenalce. (2005). Estudio socioeconómico de las familias productoras de trigo en los Departamentos de Nariño, Boyacá y Cundinamarca correspondientes a las siembras del semestre A 2005.

Fenalce. (2018). Área, producción y rendimiento de los cultivos de cereales y leguminosas. Estadísticas. URL:https://www.fenalce. org/alfa/pg.php?pa $=60$

Finagro. (2014). Perspectiva del sector agropecuario colombiano. Bogotá, Colombia.

González H. (2004). El turismo como alternativa de desarrollo para Villavicencio y el departamento del Meta. Ensayos sobre economía regional. Banco de la republica

González J. (2013). Caracterización y Tipificación de Sistemas Productivos de Leche en la X Región de Chile: un Análisis Multivariable. Tesis Licenciado en Ciencias de los Alimentos. Valdivia, Universidad Austral de Chile. 105 p.

MARD. (2019). Cadena Avícola. Dirección de cadenas pecuarias, pesqueras y acuícolas. Ministerio de Agricultura y desarrollo rural. Marzo. URL: https://sioc.minagricultura.gov.co/Avicola/ Documentos/2019-03-30\%20Cifras\%20Sectoriales.pdf_

Posada LF. (2016). Efectos socio económicos del cultivo de palma de aceite sobre los sistemas productivos campesinos en el mu- 
nicipio de Granada, Meta 2000 -2013. Pontificia Universidad Javeriana. Bogotá D.C.

PRONATA. (2003). Caracterización socioeconómica de pequeños productores de Granada y Fuente de Oro (Meta) como herramienta para el análisis hedónico de la productividad del suelo. Boletín técnico N. 42.

Salgar LM. (2004). El cultivo de arroz en Colombia. Revista semillas. Edición 22/23. Pag 2.

Scheaffer RL, Mendenhall W, Ott L. (2006). Elementos de muestreo. Madrid: Editorial Paraninfo, S.A.;

Smith R, Moreira V, Latrille L. (2013). Caracterización de sistemas productivos lecheros en la $\mathrm{X}$ región de Chile mediante análisis multivariable. Agricultura Técnica 62:375-395.
Valerio D, Acero R, Perea JM, García A; Castaldo A, Peinado JM. (2004). Metodología para la caracterización y tipificación de sistemas ganaderos. Documento de trabajo del departamento producción animal y gestión. Universidad de Córdoba. DT 1, Vol. 1, Pp.2.

Vargas L, Leitón O, Guzmán S, Sáenz F, León H. Caracterización y clasificación de hatos lecheros en costa rica mediante análisis multivariado. Agron Mesoam. 2013;24(2):257-275.

Viloria J. (2009). Geografía económica de la Orinoquia. Documento de trabajo sobre economía regional. Banco de la Republica. №113. Pág 22.
Adriana Molina: https://orcid.org/0000-0001-8975-0454 Manuel Ostos: https://orcid.org/0000-0002-4855-9407 Mario Buenaventura: https://orcid.org/0000-0002-3307-6867

Jorge Argüelles: https://orcid.org/0000-0003-2886-1542 